\title{
TÃO LONGE E TÃO PERTO: Um estudo de caso da utilização de TICs no Mestrado Profissional de Gestão e Avaliação da Educação Pública ${ }^{1}$
}

\author{
MARCOS TANURE SANABIO
}

Professor Titular da Faculdade de Administração e Ciências Contábeis (FACC) da Universidade Federal de Juiz de Fora (UFJF). Doutor em Administração (Universidade Federal de Lavras, UFLA, 2008), Mestre em Administração Pública (Fundação Getúlio Vargas, RJ, 1991) e graduado em Administração (Faculdades Machado Sobrinho, Juiz de Fora, MG, 1978). PróReitor de Infraestrutura e Gestão (PROINFRA/UFJF). Membro do Comitê Gestor Nacional do PROFIAP - Mestrado Profissional em Administração Pública - ANDIFES Conselheiro Suplente do Conselho Regional de Administração do Estado de Minas Gerais - CRA/MG Áreas de interesses: Administração Pública, Educação Pública, Educação a Distância e Empreendedorismo. E-mail: mts@caed.ufjf.br

\footnotetext{
1 Texto apresentado no XV Colóquio Internacional de Gestão Universitária - CIGU. Mar del Plata - Argentina.
} 


\title{
JULIANA ALVES MAGALDI
}

Graduada em Ciências Socias pela Universidade Federal de Juiz de Fora (1997), mestrado em Antropologia pela Universidade Federal Fluminense (2002) e doutorado em Ciência da Religião - área de concentração: ciências sociais da religião -pela Universidade Federal de Juiz de Fora (2008). Tem experiência na área de Antropologia, Sociologia e Educação, atuando principalmente nos seguintes temas: educação, religião, cultura material,consumo, teoria antropológica e sociológica. Atua como Coordenadora do Núcleo de dissertação do mestrado profissional em educação do PPGP (programa de Pós Graduaçãop Profissional em Gestão e avaliação da educação Pública) oferecido pelo CAEd da UFJF. E-mail: jmagaldi@caed.ufjf.br

\section{ELIANE MEDEIROS BORGES}

Graduada em Ciências Sociais pela Universidade Federal do Rio de Janeiro (1985), mestrado em Multimeios pela Universidade Estadual de Campinas (1995) e doutorado em Educação pela mesma Universidade (2004). É professor associado da Universidade Federal de Juiz de Fora, Faculdade de Educação. Atualmente realiza trabalhos e pesquisas nas áreas de Educação a Distância, Mídia-Educação e Comunicação, Imagem e Conhecimento. É lider do grupo Educação, Cultura e Comunicação (EDUCCO). É coordenadora UAB e Coordenadora-Geral do CEAD da UFJF. É também Coordenadora do Mestrado Profissional em Gestão e Avaliação da Educação Pública. E-mail: mborges.eliane@gmail.com

\begin{abstract}
Resumo - O presente artigo objetiva analisar a utilização das Tecnologias e Informação e Comunicação (TICs) no Mestrado Profissional em Gestão e Avaliação da Educação Pública (PPGP/CAEd/UFJF) da área de Educação (CAPES) que possibilitou a formação de Pós-graduação, stricto sensu, de 657 mestrandos, em 5 turmas (2010, 2011, 2012, 2013 e 2014), oriundos de 24 instituições públicas e privadas, de 12 estados brasileiros e dos Governos de Angola e Moçambique. Essa formação se deu a partir de metodologias pedagógicas inovadoras, como, da oferta de disciplinas online/presenciais e a elaboração de estudos de casos para realização dos trabalhos de conclusão de curso, com suporte de tecnologias online. Proposta inovadora que busca uma práxis de convivência entre o mundo acadêmico e profissional e uma formação qualificada e reflexiva, que transforma "tão longe em tão perto".
\end{abstract}

Palavras-chave: Tecnologia da Informação e Comunicação. Mestrado Profissional em Educação. Educação Pública. 
Resumen: En este trabajo se pretende analizar el uso de las tecnologías y de la información y la comunicación (TIC) en el Masters profesional en Gestión y Evaluación de la Educación Pública (PPGP / CAED / UFJF), el área de Educación Superior (Capes) que permitió la formación de post- estudios de grado, 657 estudiantes de maestría en 5 clases (2010, 2011, 2012, 2013 y 2014), procedentes de 24 instituciones públicas y privadas en 12 estados brasileños y los gobiernos de Angola y Mozambique. Esta capacitación se llevó a cabo a partir de las metodologías de enseñanza innovadoras, como el suministro de materias en línea / aula y el desarrollo de estudios de casos para lograr la realización de trabajos de curso, con el apoyo de la tecnología en línea. propuesta innovadora que busca una praxis de la coexistencia entre la formación académica y profesional y cualificado y reflexivo que transforma "en lo que va tan cerca." Palabras clave: tecnología de la información y la comunicación, maestro profesional, educación pública

\section{TÃO LONGE E TÃO PERTO: um estudo de caso da utilização de TICs no Mestrado Profissional de Gestão e Avaliação da Educação Pública}

\section{Introdução}

O artigo apresenta a experiência do Mestrado Profissional em Gestão e Avaliação da Educação Pública (PPGP/CAEd/UFJF), da Universidade Federal de Juiz de Fora, na apropriação das Tecnologias da informação e comunicação (TICs) no processo de formação.

A representatividade dos Mestrados Profissionais em Educação (MPE) no campo da formação da Pós-graduação stricto sensu é relativa e inicial. Os dados consolidados pelo Sistema Nacional de Pós-graduação (SNPG) ${ }^{2}$, demonstram que dos 5.812 cursos de Pós Graduação, 3.226 são mestrados acadêmicos (56\%), 1.997 são doutorados acadêmicos (34\%) e 589 são mestrados profissionais $(10 \%)$.

$\mathrm{Na}$ análise dos conceitos atribuídos pela Coordenação de Aperfeiçoamento de Pessoal de Nível Superior (CAPES), considerando que os MPs obtém, no máximo, conceito 5, a situação é ainda mais preocupantes. Dos $589 \mathrm{MPs}$, a sua grande maioria é conceito 3, com $70 \%$, com conceito $4,24 \%$, e apenas $6 \%$, com conceito 5 . A comparação com o total dos cursos acadêmicos

2 Dados da Coordenação de Aperfeiçoamento de Pessoal de Nível Superior (CAPES), atualizado em 20/03/2015. 
e profissionais justifica a relatada preocupação, pois a relação entre os conceitos de 3 a 7 são na ordem de $27 \%, 38 \%, 20 \%, 9 \%$ e $5 \%$, respectivamente, conforme demonstrado na Tabela 1

Tabela 1: Conceitos dos cursos de pós-graduação

\begin{tabular}{|c|c|c|c|c|c|c|c|c|}
\hline \multirow{2}{*}{ Conceitos } & \multicolumn{7}{|c|}{ Totais de Cursos de pós-graduação } \\
\cline { 2 - 11 } & \multicolumn{2}{|c|}{ Total } & \multicolumn{2}{c|}{ M } & \multicolumn{2}{c|}{ D } & \multicolumn{2}{c|}{ P } \\
\cline { 2 - 11 } & Qte & $\%$ & Qte & $\%$ & Qte & $\%$ & Qte & $\%$ \\
\hline 3 & 1.579 & $27 \%$ & 1.121 & $35 \%$ & 47 & $2 \%$ & 411 & $70 \%$ \\
\hline 4 & 2.224 & $38 \%$ & 1.118 & $35 \%$ & 961 & $48 \%$ & 145 & $24 \%$ \\
\hline 5 & 1.186 & $20 \%$ & 578 & $18 \%$ & 575 & $29 \%$ & 33 & $6 \%$ \\
\hline 6 & 535 & $9 \%$ & 265 & $8 \%$ & 270 & $14 \%$ & 0 & $0 \%$ \\
\hline 7 & 290 & $5 \%$ & 145 & $4 \%$ & 145 & $7 \%$ & 0 & $0 \%$ \\
\hline Total & 5.814 & $100 \%$ & $\mathbf{3 . 2 2 7}$ & $100 \%$ & 1.998 & $\mathbf{1 0 0 \%}$ & $\mathbf{5 8 9}$ & $\mathbf{1 0 0 \%}$ \\
\hline
\end{tabular}

Fonte: adaptado de SNPG/CAPES, 2015

Considerando as 49 áreas de avaliação da CAPES, os MPs são ofertados em 46 áreas, excetuando-se (i) Antropologia/Arqueologia, (ii) Filosofia/Teologia, Subcomissão Filosofia e (iii) Serviço Social. Observa-se, ainda, que três áreas de avaliação: (i) Interdisciplinar, (ii) Ensino e (iii) Administração, Ciências Contábeis e Turismo destacam pela oferta dos cursos, ficando a área da Educação, em 4o lugar, 33 ofertados e um percentual de 10,4\%, exposta na Tabela 2.

Tabela 2: Distribuição dos MPs por área de Avaliação da CAPES

\begin{tabular}{|c|c|c|c|}
\hline N. & ÁREA AVALIAÇÃO & Qte & $\%$ \\
\hline 1 & INTERDISCIPLINAR & 79 & $13,4 \%$ \\
\hline 2 & ENSINO & 67 & $11,4 \%$ \\
\hline 3 & ADMINISTRAÇÃO, CIÊNCIAS CONTÁBEIS E TURISMO & 61 & $10,4 \%$ \\
\hline 4 & EDUCAÇÃO & 33 & $5,6 \%$ \\
\hline
\end{tabular}

Fonte: adaptado de SNPG/CAPES, 2015 
Para que essa experiência seja compreendida em sua totalidade, o artigo na sua seção 1 descreve a práxis do PPGP/CAEd/UFJF. A seção 2 é destinada ao detalhamento da utilização das TICs no mestrado profissional, em recorte especial, das disciplinas online/presencial e do trabalho final (dissertação), e o papel da tecnologia como peça chave que permite a execução 3 de uma proposta de amplitude territorial tão vasta Por fim, as considerações finais e as referências utilizadas no trabalho.

\section{PRÁXIS DO MESTRADO PROFISSIONAL EM GESTÃO E AVALIAÇÃO DA EDUCAÇÃO PÚBLICA}

O Programa de Pós-Graduação em Gestão e Avaliação da Educação Pública (PPGP/CAEd/ UFJF) foi constituído a partir dos esforços realizados no âmbito da Universidade Federal de Juiz de Fora (UFJF), no sentido de proporcionar maior aproximação entre a instituição e as redes públicas de ensino de educação básica, mediante à oferta de formação de educadores e gestores educacionais em níveis cada vez mais elevados (SANABIO E MAGALDI, 2014 e 2015) de 790 mestrandos, em 6 turmas (2010, 2011, 2012, 2013, 2014 e 2015), oriundos de 24 instituições públicas e privadas, de 12 estados brasileiros e dos Governos de Angola e Moçambique.

O PPGP/CAEd/UFJF se vincula diretamente ao Centro de Políticas Públicas e Avaliação da Educação (CAEd), associado à Faculdade de Educação da UFJF. O CAEd é um centro de avaliação, formação, gestão e pesquisa na área de gestão da educação pública e no desenvolvimento de tecnologias de administração escolar, com atuação em parceria com redes educacionais do Governo Federal, Estaduais, Municipais e organizações (CAEd, 2015).

A inserção social do CAEd/UFJF, e por consequência do PPGP/CAEd/UFJF, é relevante através de Programas de Avaliações Educacionais, Programas de Avaliação Especial, Programas de Formação nas modalidades presencial e EaD e desenvolvimentos de softwares aplicados as Redes de Ensino, em parcerias com as Secretarias Estaduais de Educação de Minas Gerais, do Rio de Janeiro, do Rio Grande do Sul, do Ceará, de Pernambuco, do Acre, do Amazonas, de Goiás, do Mato do Grosso do Sul, do Piauí, de São Paulo, do Espírito Santo, de Rondônia, da Paraíba, do Paraná, da Bahia e do Pará. Como, ainda, ações e atividades realizadas nos municípios de Belo Horizonte/MG e Ipojuca/CE. Parcerias com o Instituto UNIBANCO, a Fundação Roberto Marinho, o INEP, o SENAI e o SESI completam a lista de interfase do Programa.

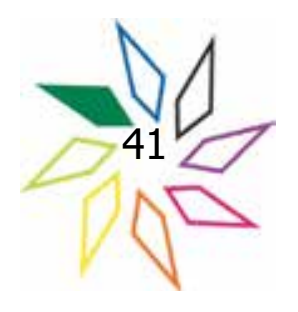


Pardim e Maccari (2014) ao analisarem o PPGP/CAEd/UFJF, em publicação da RBPG, intitulada de $A$ educação online na pós-graduação stricto sensu: a experiência de um Mestrado Profissional em Gestão e Avaliação da Educação Pública retrata fielmente a criação do curso:

... a UFJF, enviou à Capes, no ano de 2009, a proposta do Programa de PósGraduação Profissional (PPGP) em Gestão e Avaliação da Educação Pública, a ser oferecido na modalidade semipresencial. Aprovado na área de educação, com conceito 3, este curso atende o que preveem o PNPG e a Portaria $\mathrm{n}^{\circ} 286$, de 21 de março de 2011, pois visa melhorar a educação pública brasileira, formando profissionais capazes de atuar à frente de instituições de ensino, desde a educação infantil até o ensino médio, uma vez que o setor educacional é estratégico para o desenvolvimento social, econômico e cultural da sociedade brasileira.

A única e exclusiva ressalva é que, atualmente, o Programa atende profissionais vinculados ao ensino superior, prioritariamente da UFJF, com outros mestrandos da Universidade Federal de Viços (UFJF), Instituto Federal do Paraná (IFPR), do Ministério da Educação (MEC) e do Instituto Nacional de Estudos e Pesquisas Educacionais Anísio Teixeira (INEP).

Barros, Valentim e Melo (2005) ao identificarem que há procura pelos MPs para formações e capacitações de pessoal ser realizado por profissionais colocados, seja no setor público ou privado para aprimoramento do conhecimento, e com ênfase na descoberta de soluções para sua área de interesse, sem necessariamente enveredar por mestrados acadêmicos. Sendo assim, a leitura do projeto pedagógico do PPGP/CAEd/UFJF coaduna 4 com os autores, pois o seu objetivo é proporcionar os conhecimentos, desenvolver as competências e habilidades, além de promover as qualidades profissionais necessárias ao exercício eficiente dos novos papéis que são atribuídos ao gestor da educação pública. De modo geral, inscreve-se nas políticas que têm por objetivo o estabelecimento de padrões de desempenho para diretores de unidades de ensino, base para a implantação de programas de avaliação da gestão escolar e de certificação profissional (SANABIO e MAGALDI, 2014 e 2015).

Fischer (2005, p. 24) corrobora com a questão, ao ensinar que "aprendizagem pela experiência, pela prática ou a partir das práticas está no centro das discussões na formação de gestores". A autora colabora na compreensão do fenômeno dos MPs, ao classificar o tipo de curso em dois modelos: generalista e focalizado. O modelo generalista afeito a área da Administração, se propõe a formação estratégica de profissionais e revisão de práticas gerenciais exercidas pelos 
mestrados. Já o modelo focalizado forma e capacitam profissionais de setores específicos, como das áreas de saúde, educação, entre outros. A procura destes profissionais, em geral, é para solucionar e resolver questões focais, em determinadas situações, instrumentais e de políticas públicas.

Ao cotejar as explicações de Fischer (2005) e os objetivos do PPGP/CAEd/UFJF cria-se uma relação direta, podendo-se a atribuir ao curso o modelo focalizado.

Vencidos os debates sobre importância dos MPs, tanto na formação de profissionais cujos mestrandos não irão compor quadros do ensino superior, ou mesmo as suas tipificações e modelos, é fundamental descrever e discutir a organicidade do PPGP/CAEd/UFJF, na presente seção do artigo, como: área de concentração, linhas de pesquisa, corpo docente, disciplinas e trabalho final (dissertação). Aqui iremos tratar e todos, exceto das disciplinas e do trabalho final, objeto da próxima seção, por utilizar as Tecnologias de Informação e Comunicação (TICs). A fonte das informações e inferências são dos Relatórios Sucupira - Mestrado Profissional em Gestão e Avaliação da Educação Pública, versões 2014 e 2015 (SANABIO E MAGALDI, 2014 e 2015).

O PPGP/CAEd/UFJF é formatado em única linha de concentração: Gestão da Educação Pública. Com quatro as linhas de pesquisa: 1. Modelos, Instrumentos e Medidas Educacionais; 2. Gestão, Avaliação e Reforma da Educação Pública; 3. Equidade, Políticas e Financiamento da Educação Pública e 4. Avaliação, Currículos e Desenvolvimento Profissional de Gestores e Professores da Educação Básica.

Desse cenário, decorre uma valorização crescente do papel do gestor da educação pública. O diretor da escola vê-se frente a um contexto de maior liberdade para tomar decisões, especialmente no que diz respeito às estratégias pedagógicas e aos programas de ensino, e a consequente responsabilização pela realização dos objetivos da escolarização básica, muitas vezes, objeto de acordos de metas específicos com o poder público.

Por sua vez, o gestor que atua nas estruturas municipais e regionais da administração da educação pública vê-se obrigado a lidar com novos processos de coordenação e avaliação do trabalho desenvolvido nas escolas, distanciando-se do modo burocrático tradicional, centrado no controle de processos administrativos e na fiscalização do cumprimento de uma infinidade de normas, muitas vezes inócuas, e oferecer o suporte necessário às escolas e aos seus profissionais, por meio de programas e políticas públicas desenhadas para corrigir deficiências e promover a qualidade do ensino, para o que também é essencial a definição de prioridades e objetivos, o

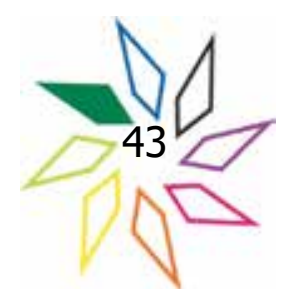


monitoramento da execução e a avaliação dos resultados e a elaboração cuidadosa dos orçamentos da educação pública.

\section{TICs e PPGP/CAEd/UFJF}

A utilização das Tecnologias da Informação e Comunicação (TICs) é uma das características marcantes e inovadora do PPGP/CAEd/UFJF. Trataremos, aqui, das disciplinas, do trabalho final e da dimensão das turmas do curso, que assumem tal proporção, única e exclusiva pela adoção de tecnologias online.

\subsection{As disciplinas}

A partir de 2013 o PPGP/CAEd/UFJF implanta nova estrutura curricular, decorrente de um processo de avaliação interna e da experiência dos anos de 2010 a 2012, parametrizada na concentração das disciplinas no $1^{\circ}$ ano e uma maior disponibilidade dos mestrandos, no $2^{\circ}$ ano para realização da sua dissertação.

O mestrando precisa integralizar 38 créditos, sendo 1 crédito equivalente a 15 horas/aula, distribuídos em grandes grupos de disciplinas:

1. Formação Profissional - 10 créditos

2. Estudos Transversais - 6 créditos

3. Formação Básica -3 créditos

4. Tópicos Especiais - 7 créditos

5. Dissertação - 12 créditos

De acordo com o modelo híbrido de organização curricular do PPGP/CAEd/UFJF, as disciplinas são ofertadas em dois tipos de modalidade: presencial/online e presencial. As disciplinas da modalidade presencial/online são todas de 2 (dois) créditos, distribuídas em 16 horas online e 16 horas presenciais. Caso específico das disciplinas dos grupos de Formação Profissional e Estudos Transversais.

À guisa de explicação das disciplinas na modalidade presencial/online apresenta-se a seguir sua modelagem. As disciplinas são iniciadas na semana presencial, quando os docentes fazem breve apresentação dos conteúdos, das atividades online e presenciais, 
bibliografias, e invariavelmente, discutem assuntos inerentes aos temas a serem tratados. Após, inaugura-se a fase online desenvolvida em 16 (dezesseis) semanas, distribuídas em 8 (oito) blocos/temas quinzenais. A presente fase (online) é suportada por um Ambiente Virtual de Aprendizagem (AVA), no software livre Moodle, para turma $2013^{3}$ e para turma $2014^{4}$.

Nas atividades online é utilizada uma coleção de recursos e mídias digitais didáticas, como: textos e artigos científicos, vídeo-aulas, podcast, multimídias, fóruns de discussão, tarefas (trabalhos específicos), Laboratório de Avaliação (recurso do Moodle), Wikis, entre outros. A responsabilidade pela produção dos recursos e mídias do PPGP/CAEd/UFJF fica a cargo de um setor de Design Instrucional, especialmente criado no CAEd para essa função. Os materiais são concebidos pelos docentes responsáveis pelas disciplinas.

A mediação nas disciplinas na fase online é realizada pelos docentes assessorados por agentes de suporte acadêmico (ASA), que exercem a função de tutoria. Estes são mestres ou doutores, com aderência ao conteúdo das disciplinas de que participam. As equipes das disciplinas (docente e ASAs) realizam reuniões pedagógicas semanais para o acompanhamento da disciplina, planejamento e correção das avaliações. É importante relatar que as turmas são divididas em grupos de no máximo 30 alunos, ficando, assim, cada ASA responsável por uma turma.

No encontro presencial que ocorre após a fase online, os mestrandos realizam atividades presenciais da disciplina, quando o docente completa os conteúdos e/ou revisa os conteúdos da fase online. No momento presencial, são realizadas avaliações, seja com provas ou trabalhos. Para aprovação na disciplina o mestrando precisa obter o mínimo de $70 \%$ da pontuação, conforme Regimento Geral da Pós-Graduação/UFJF, sendo que, as avaliações online totalizam no máximo $49 \%$, e as avaliações presenciais no mínimo de $51 \%$ dos pontos distribuídos.

A experiência com as disciplinas da modalidade presencial/online que combina momentos online e presenciais tem se revelado muito promissora. Ao mesmo tempo em que a tecnologia cria possibilidades de aproximação entre docentes/ASAs e mestrandos nas disciplinas nos momentos online, pelo uso de recursos e mídias digitais, os momentos presenciais são enriquecidos pelo emprego de tecnologias na sala de aula, o que torna o processo de ensino mais dinâmico e atrativo. A possibilidade de lidar com atividades que envolvem leitura e análise de dados, estabelecimento de metas de escolarização e definição de medidas de política educacional em casos fictícios

3 http://www.ppgp2013.caedufif.net/login/index.php

4 http://www.ppgp2014.caedufif.net/login/index.php

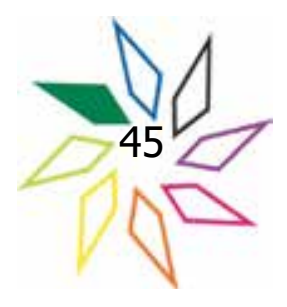


elaborados para as atividades, discussões e avaliações das disciplinas é mais um aspecto de inovação do PPGP/CAEd/UFJF. As referências bibliográficas vindas da produção acadêmica de pesquisadores brasileiros e estrangeiros se associam a exercícios práticos que pretendem desenvolver habilidades necessárias ao gestor da educação em um contexto altamente desafiador - a urgência de oferecer educação pública de qualidade. De modo resumido apresentamos a estrutura curricular padrão, conforme Figura 1.

\section{Figura 1: Grade curricular padrão do PPGP/CAEd/UFJF}

\section{Grade Curricular}
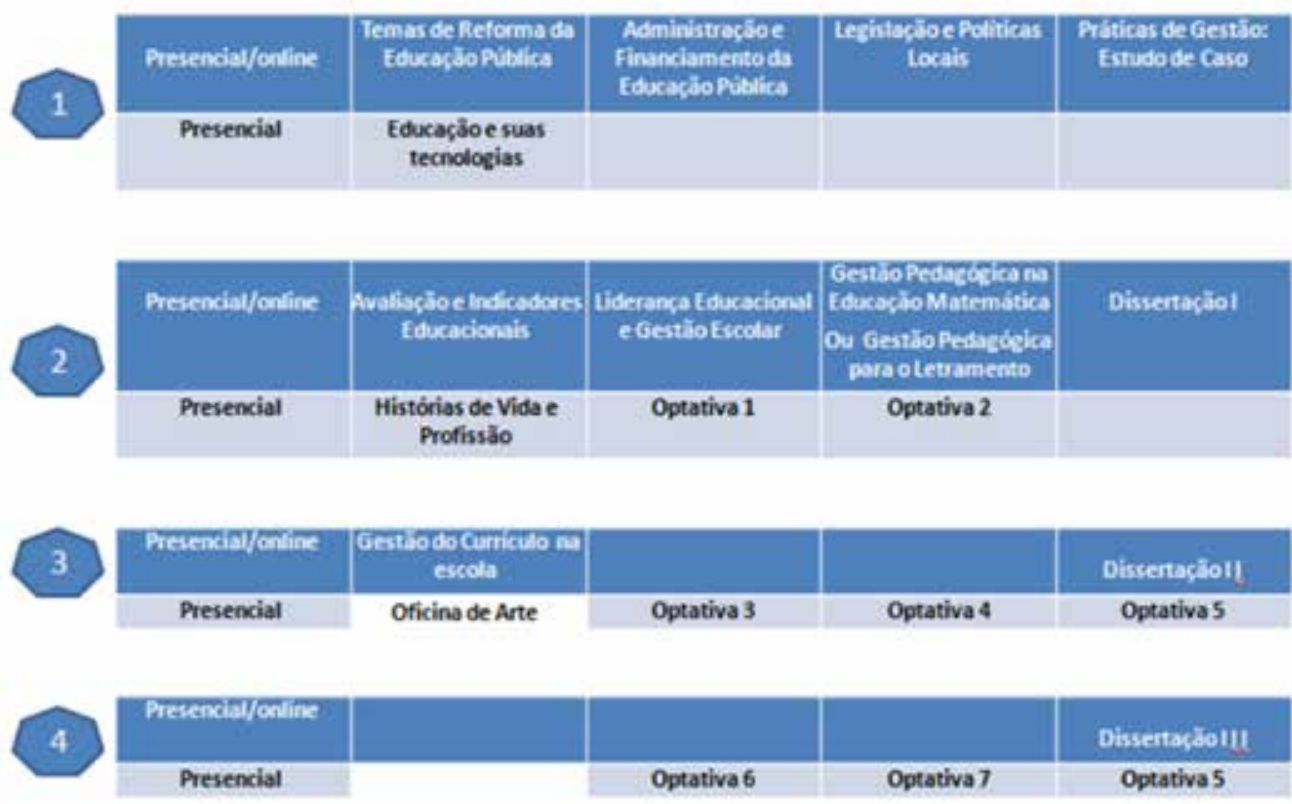

Fonte: Elaborado pelos autores

As tecnologias de informação e comunicação (TICs) têm sido empregadas nos momentos online do curso. Isso compõe o que chamamos de um modelo híbrido de currículo. O emprego de tecnologia tem servido para aproximar estudantes e professores nos momentos em que esses se encontram dedicados às suas atividades de gestores. 
As possibilidades criadas pela Web 2.0 permitem o compartilhamento de recursos multimídia que aproximam professores e estudantes quando estão fisicamente afastados. Uma equipe de designers instrucionais desenvolve recursos como leituras multimídia (slides com recursos em flash, links direcionados a textos e vídeos), que permitem a movimentação dos estudantes por diferentes materiais didáticos digitais. Podcasts transmitem seminários realizados entre os professores das disciplinas e os agentes de suporte acadêmico, seus auxiliares para a mediação de conteúdos. O curso é oferecido no que se convencionou chamar de modelo híbrido de educação, compreendendo a hipermodalidade, múltiplos recursos tecnológicos e encontros presenciais.

Tal constatação é defendida por Beloni (2009), ao relatar que as TICs apresentam uma contemporaneidade, tanto nacional, como internacional para atender o processo de formação de uma sociedade moderna. Para Borges ( 2010, p. 57), os AVAs na sua maioria a partir da Plataforma Moodle proporcionam recursos síncronos e assíncronos, como, por exemplo, fóruns, chats, wikis, entre outros. A autora, afirma simbolicamente, "no lugar da distância, presenças". Preti (2010, p. 4) corrobora com Borges (2010), ao afirmar, categoricamente, "podemos falar em EDUCAÇÃO SEM DISTÂNCIAS! Não somente porque é possível ser realizada, como por ser bandeira de luta a ser levada adiante para as próximas décadas, por nós, educadores!"

Um dos espaços que revelam toda a potencialidade da formação no PPGP através das TICs são os fóruns de discussão das disciplinas, onde interagem professores, alunos/gestores e ASAs. Esse espaço de interação calcado nas leituras teóricas, mas também nas experiências educacionais permite um intercambio contínuo entre os envolvidos.

Ainda, Borges (2010) ensina que a distância entre os discentes e docentes requer a utilização de recursos pedagógicos, com a produção de materiais didáticos para as disciplinas, em um processo continuo de experimentação e aprimoramento.

Para Moura Castro (2005, p. 20) a utilização de tecnologia e da modalidade semipresencial ou online/presencial é um recurso pedagógico valido para os MPs. Partindo da constatação que os mestrandos são sujeitos, na sua maioria maduro e com um grau de motivação elevado, que trabalham e com família, as estruturas didáticas dos cursos apoiadas por TICs, racionalizam o ensino na otimização do tempo dos mestrandos, e o avanço destas ferramentas tornam os cursos eficientes e eficazes, com qualidade. A legitimação dos meios tecnológicos, na interpretação de Moura Castro (2005), "não pode continuar a ser uma cruzada, uma guerra santa, sempre perdida!".

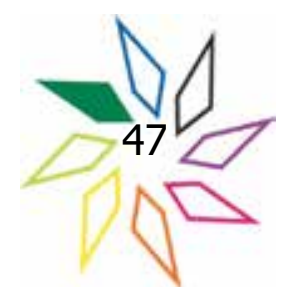


Ensino convencional ou simulação?, questiona Fischer (2005, p. 28). Ensino presencial e semipresencial, em resumo, a autora afirma que um MP deve ser norteado "por princípios de flexibilidade organicidade, inovação e aplicabilidade. Esse parece ser o maior desafio".

A Figura 2 demonstra o Ambiente Virtual de Aprendizagem (AVA), da disciplina Administração e Financiamento da Educação Pública, em especial os conteúdos programáticos da $2^{\circ}$ quinzena, intitulado de Gestão Social. Observa-se, ainda, que, como relato anterior, as disciplinas online/presencial são ministradas em 8 quinzenas.

\section{Figura 2: Disciplina Administração e Financiamento da Educação Pública - rótulo inicial}

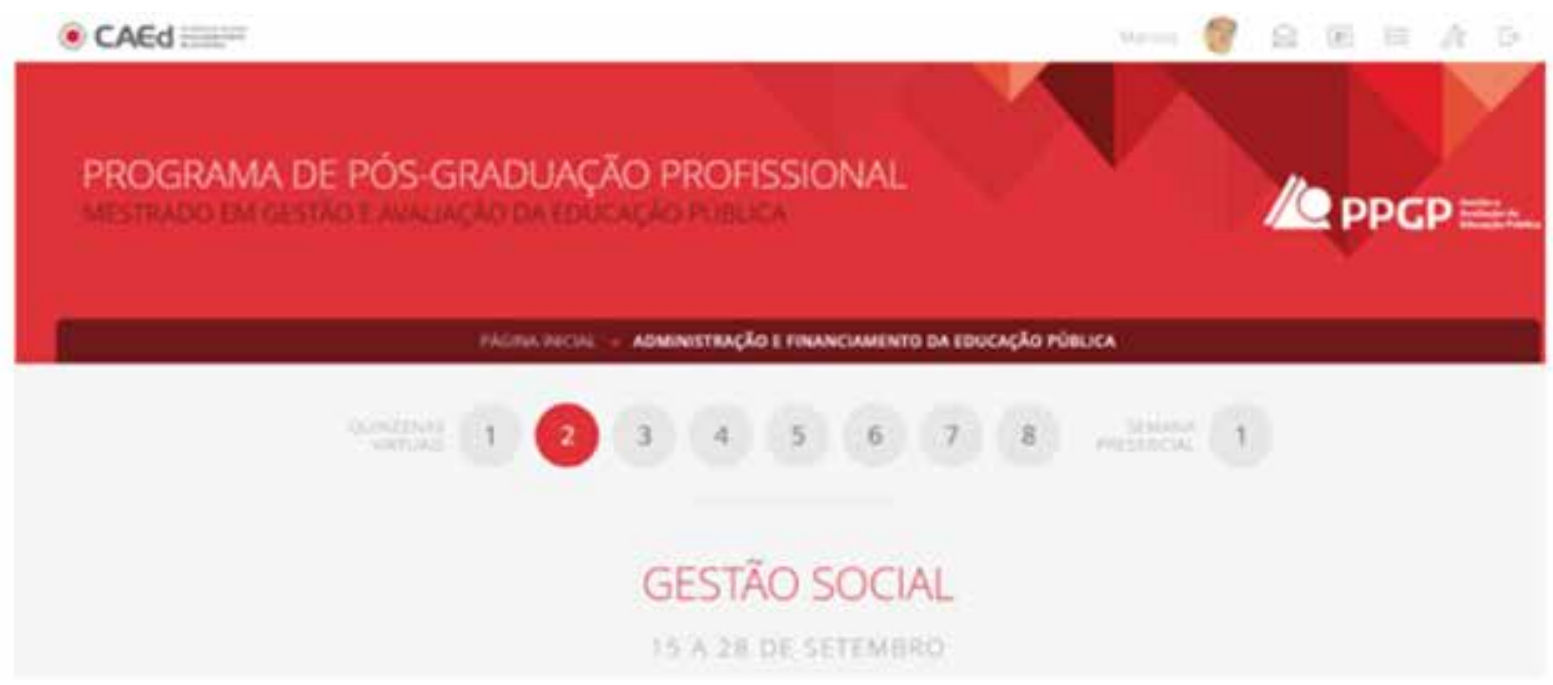

Fonte: PPGP/CAEd/UFJF, 2015 
Na Figura 3 são descritas as atividades e indicações de leituras para a $2^{\text {a }}$ quinzena.

\section{Figura 3: Disciplina Administração e Financiamento da Educação Pública, descrição}

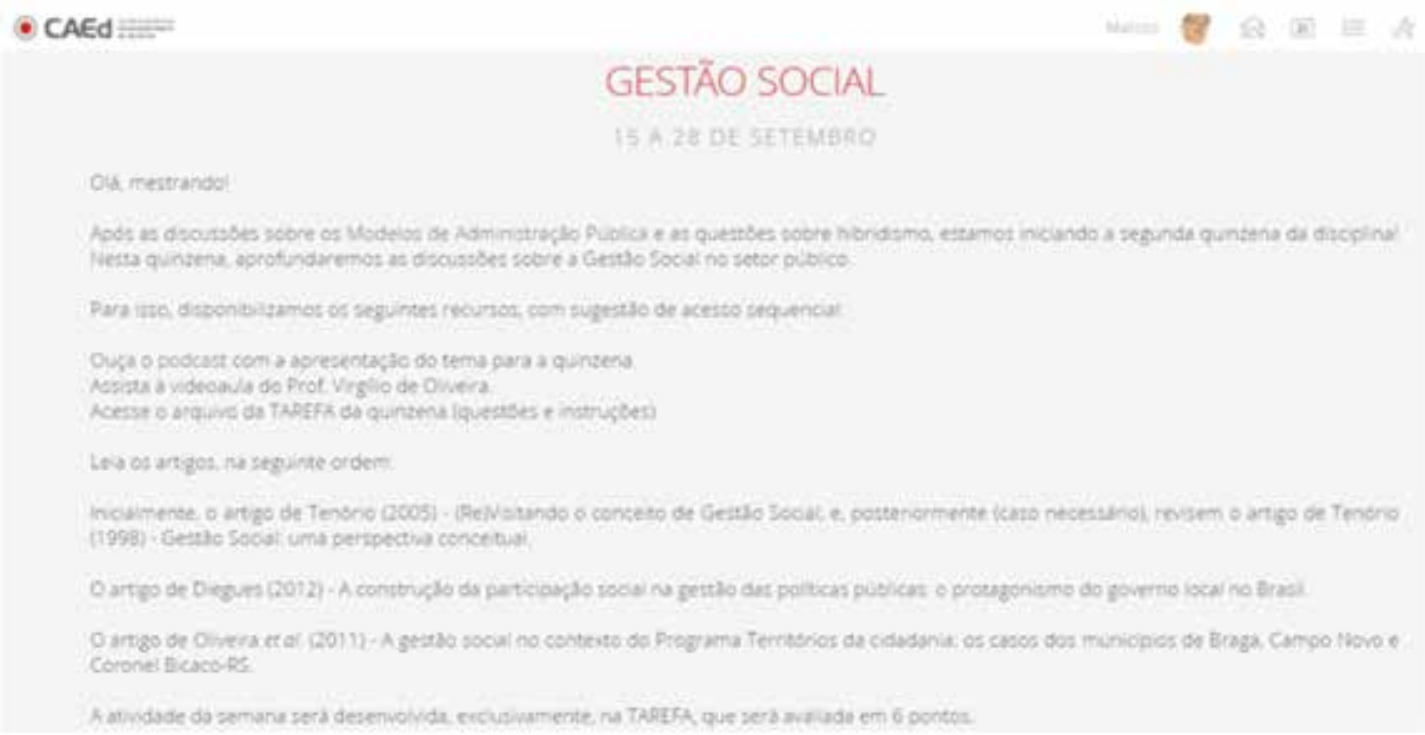

Fonte: PPGP/CAEd/UFJF, 2015 
Na Figura 4 visualizam-se os materiais didáticos, sendo um Podcast, uma videoaula, os textos para leitura e o Fórum para discussão.

Figura 4: Disciplina Administração e Financiamento da Educação Pública, materiais

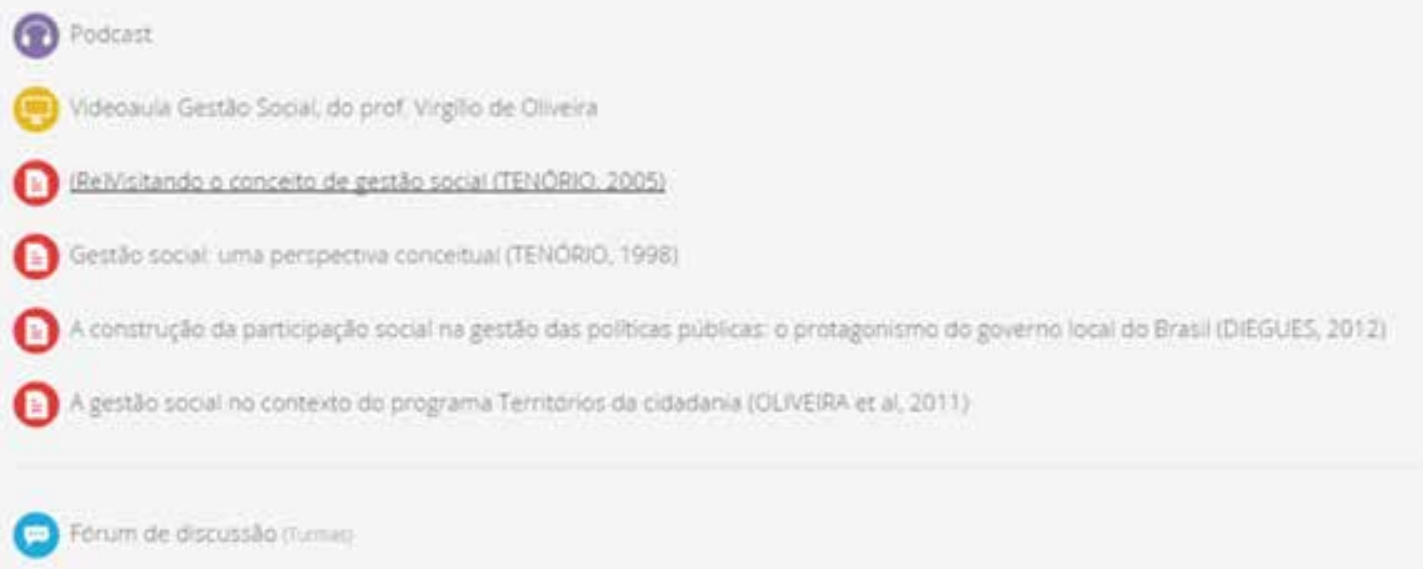

Fonte: PPGP/CAEd/UFJF, 2015

\section{Trabalho final/Estudo de caso: uma experiência inovadora de formação na orientação e na utilização das TICs}

Dentre as disciplinas obrigatórias, destacam-se quatro que se constituem como a espinha dorsal do Programa no tocante à produção discente das dissertações. Tais disciplinas são oferecidas nos quatro semestres do curso respeitando a seguinte ordem: Estudo de Caso, Dissertação I, Dissertação II e Dissertação III. De modo esquemático, a Figura 5 apresenta o sequenciamento das disciplinas e sua vinculação com o trabalho final do mestrado profissional. 


\section{Figura 5: Disciplinas vinculadas ao trabalho final/Estudo de Caso}

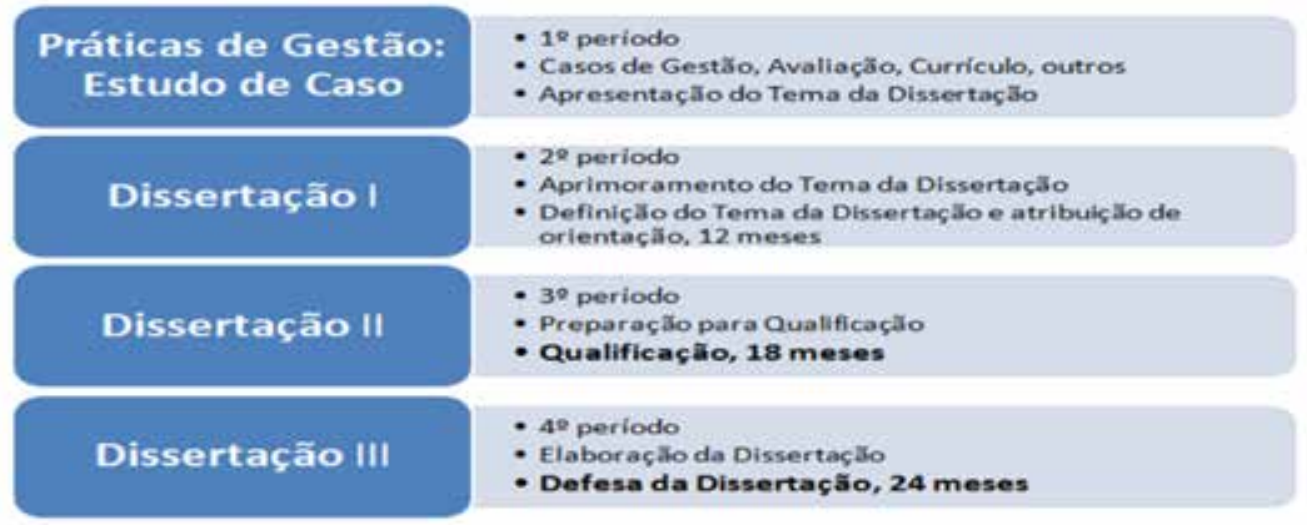

Fonte: Elaborada pelos autores

Antes do detalhamento da metodologia e das disciplinas, cabe retornar as discussões entre as diferenças ou possíveis diferenças dos mestrados acadêmicos e profissionais, pela via do trabalho final (MOURA CASTRO, 2005; FISCHER, 2005). Iniciamos com Moura Castro (2005, p. 19), que ilustra o perfil dos mestrandos nos MPs, compostos por profissionais, empregados de empresas, servidores públicos, professores que desejam avançar no conhecimento. Em tom sarcástico, o autor infere que estes profissionais trabalham, tendo somente, as noites, finais de semanas e férias para estudar. Agrega-se, como no caso do PPGP/CAEd/UFJF, todos têm famílias, esposas (os), companheiros (as), filhos (as) e susceptíveis às enfermidades e contra tempos. Alerta o autor, que se uma Universidade deseja criar um MP deve no mínimo aceitar, tais condições.

A Profa. Tânia Fischer (2005, p. 28) aponta alguns tabus vivenciados na academia. O primeiro da não valorização dos cursos acadêmicos pelas práticas profissionais a partir de experiências no mundo real. Um segundo motivo da maior valorização da pesquisa e da produção bibliográfica, e não da produção tecnológica ou técnica. Um terceiro motivo do trabalho final do MP que se assemelha às dissertações acadêmicas. A procura de uma metodologia apropriada e própria para o trabalho final é a meta: "o seu conteúdo pode incluir, por exemplo, resultados de estudos de casos, desenvolvimentos e descrição de metodologias, tecnologias e softwares, patentes que decorrem de pesquisas aplicadas"

Para entendermos a trajetória percorrida pelo discente nessas disciplinas que se inicia com "Práticas de Gestão: estudo de Caso" é fundamental que apresentemos a metodologia eleita pelo 
Programa como a ideal para a construção das dissertações com fins de intervenção: a metodologia do Caso que foi adotada no programa se estabeleceu a partir do acordo de cooperação com a Graduate School of Education, da Universidade Harvard. Ela tem como base os casos de ensino habitualmente usados nas áreas de Administração e Direito e adotados em Harvard na área de Educação. Aplicado nas universidades brasileiras, o método de estudo de caso passa a ser denominado de case. Conquista notoriedade nos mesmos campos em que antes fora aplicado na Universidade de Harvard, em cursos de graduação em Direito, Administração e na área médica.

O método de caso como ferramenta de ensino possibilita ao futuro profissional uma percepção mais apurada das questões e dos problemas a serem enfrentados por ele no mercado de trabalho. Nesse sentido, torna-se uma ferramenta em potencial para as demandas impostas à academia contemporânea que, cada vez mais, volta-se à formação de um profissional autônomo e dinâmico frente ao mercado de trabalho.

Entendemos que essa ferramenta de ensino possibilita ao estudante tornar-se responsável pela construção de seu próprio conhecimento, na medida em que ele é retirado de um modelo de pensamento oficial sancionado de cima para baixo, para um pensamento em que ele próprio deve ser capaz de interpretar uma multiplicidade de significados a ele impostos.

No PPGP/CAEd/UFJF adotamos o método de estudo de caso como uma ferramenta que possibilita ampla discussão entre alunos, professores e tutores, de modo que se estabeleçam relações entre a perspectiva teórica e a dimensão prática do caso analisado, mas fazemos isso dialogando com a proposta do estudo de caso qualitativo mais adotado na área de ciências sociais, especialmente, na antropologia.

A diferença dessas abordagens pode ser percebida na forma como enunciamos a questão, enquanto o primeiro método é utilizado como ferramenta pedagógica, ou seja, voltado para o ensino, este método destina-se à pesquisa. Apesar dessa diferença, existe entre os métodos uma complementaridade, pois ambos se estruturam em torno do olhar sobre um contexto empírico específico.

A opção feita no PPGP/CAEd/UFJF é pela elaboração de caso por parte dos mestrandos que tenham como protagonista um gestor. Por esse prisma se assemelha ao caso de ensino, mas por outro lado devem ser casos empíricos. A apropriação dos dados sobre esse caso é realizada através de pesquisa que dialoga com o método de estudo de caso, mas não se restringe a ele, incorporando, dependendo da temática e da extensão do caso, técnicas quantitativas de pesquisa. 
O resultado são casos empíricos, ricos em descrição, que podem ser usados por outros gestores para pensarem as suas realidades e que trazem ao final uma proposição de intervenção na realidade pesquisada.

Sendo assim, os alunos, no seu primeiro semestre, convivem intensamente com o método, conhecendo cases que os fazem questionar problemas do seu cotidiano profissional, utilizando como elemento ampliador das alternativas para os gestores o conhecimento que é apresentado nas demais disciplinas do semestre. Ao fim dessa disciplina, o aluno iniciará o processo de definição do caso de gestão que pesquisará em sua dissertação. Esse caso deve, preferencialmente, ter lugar no ambiente de trabalho do docente para que o mesmo possa problematizar a sua prática profissional.

Na disciplina Dissertação I, que possui um cunho metodológico, o discente é levado a construir o seu caso, para fazer isso ele deve sofisticar o seu olhar; uma vez que passa a levar em conta ângulos, antes negligenciados. Ao final desse semestre, ou seja, ao fim do primeiro ano de mestrado, o caso deve estar bem delineado e descrito baseado em evidências claras. Dessa forma, em um ano de curso, a grande maioria das disciplinas obrigatórias, com exceção de Liderança Educacional e gestão Escolar e das eletivas já foram cursadas, isso permite ao aluno o diálogo com esse referencial e construir o caso que irá investigar a partir dessa interação. Esse caso deve estar baseado em um problema de pesquisa que deve ser empírico e posto para um gestor educacional.

Na disciplina de Dissertação II o discente desenvolve a dissertação na parte descritiva e analítica. O semestre é concluído com as bancas de qualificação daqueles que conseguiram atingir o nível estabelecido pelo Programa. No último, os alunos cursam Dissertação III, esse é o momento de absorver as considerações da banca de qualificação e do desenvolvimento do plano de intervenção.

Outro ponto que merece ser destacado é a forma como a orientação é operacionalizada no PPGP. Como nos demais Programas, contamos com a orientação dos professores permanentes e dos colaboradores, mas para auxiliar esses profissionais temos uma equipe denominada Núcleo de orientação institucional. Os profissionais que atuam no Núcleo são mestres e doutores nas grandes áreas as quais os professores do PPGP se vinculam, a saber, Educação, Administração e Ciências Sociais. Desses, 9 atuam presencialmente 40 horas semanais, e são chamados de Suporte Acadêmico, outros 14 atuam 15 horas à distância e 5 horas presenciais, são denominados assistentes de orientação, todos dedicando-se às orientações das dissertações.

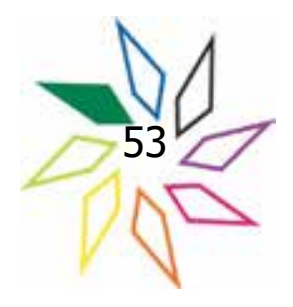


A dinâmica da interação à distância demanda, por sua vez, a mediação contínua através da plataforma Moodle, espaço no qual toda a pesquisa e o texto da dissertação são construídos. A orientação através dos textos, como é feito na plataforma exige mais tempo disponível do que a modalidade tradicional no qual os encontros podem ser frequentes.

\subsection{Turmas e amplitude}

Importante salientar, que a utilização das TICs foi e será uma estratégia pedagógica para suporte a proposta do mestrado profissional, considerado como uma formação em larga escala, com qualidade. A Tabela 3 apresenta a amplitude do corpo discente, como um número representativo de 657 alunos, em 5 turmas, vinculados à 24 instituições dos governos municipais, estaduais e federais, dos governos de Angola e Moçambique, UNIBANCO, FADEPE e franqueados (demanda aberta). 
Tabela 3: Turmas ano, vagas por conveniados e percentuais:

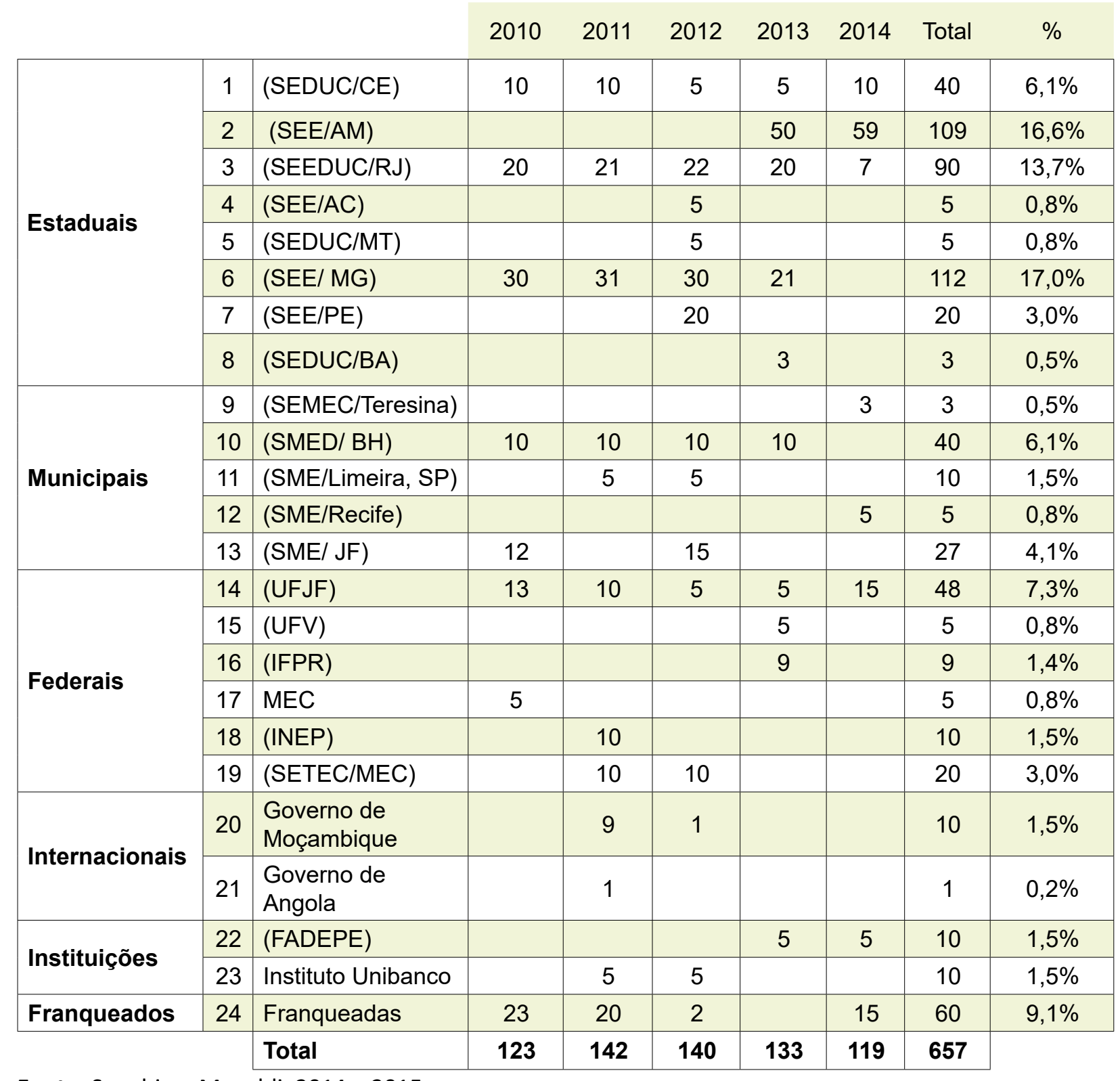

Fonte: Sanabio e Magaldi, 2014 e 2015 


\section{Considerações finais} p. 17):

Resgatamos um questionamento e uma, por assim dizer, profecia de Mora Castro (2005,

Não obstante, o que está freando o desenvolvimento do mestrado profissional é a sua estrutura atrelada à $\mathrm{PG}$ acadêmica que lhes tira a vida própria e os converte em prêmios de consolação ou mendigos, no Olimpo dos cursos acadêmicos. A estrutura presente condena os mestrados profissionais a uma mímica da vida acadêmica e da pesquisa "científica" totalmente inapropriada para sua índole profissional.

O PPGP/CAEd/UFJF vive e convive no mundo da UFJF, com um corpo docente na sua essência acadêmico e atrelado nas métricas de produção científica impostas pelo critérios de avaliação da área da Educação, pautados pela CAPES. O desejo de desatrelar é latente e forte, mas o macrossistema é poderoso e global. Por outro lado, a multidisciplinaridade do corpo docente é um fator positivo, porém requer um esforço importante na coordenação e na sua gestão.

Contudo, a sua inovação pedagógica, seja na oferta de disciplinas online/presencial, de um trabalho final que dá privilegio ao estudo de caso e por consequência um Plano Ação Educacional (Plano de Ação Educacional), com modelagem diferenciada dos mestrados acadêmicos, da experiência do CAEd no relacionamento imbricado com as redes de ensino nos níveis federal, estadual e municipal e da amplitude, em larga escala, da formação das turmas por 24 instituições, em um breve período de existência, podem ser indicações de uma história de sucesso nos MPs, e quem sabe, um "caso de gestão" para ser estudado e detalhado. Não para ser modelo, mas para parametrizar as mudanças propagadas por Ribeiro (2005), Fischer (2005), Moura Castro (2005), Agopyan e Lobo (2007), entre outros tantos que discutem o tema.

Pode-se resumir, a citação de Pardim, e Maccari (2014), ao entrevistar a Profa. Dra. Beatriz de Basto Teixeira, Vice-Coordenadora, à época, quando da realização do trabalho sobre o PPGP/CAEd/UFJF:

A entrevistada demonstra muito entusiasmo ao falar sobre o curso, uma vez que, além da relevância da temática, a semipresencialidade fez com que muitos alunos pudessem ter acesso a ele. Outro ponto destacado foi a possibilidade de formar-se em serviço, aliando teoria e prática. 
O PPGP/CAEd/UFJF é recente, jovem e inovador, com um longo caminho, um futuro desafiador e que busca uma práxis de convivência entre o mundo acadêmico e profissional, que transforma "tão longe em tão perto".

\section{REFERENCIAS}

Agopyan, Vahan e Lobo, Roberto. O futuro do Mestrado Profissional. Revista Brasileira de Pós-Graduação, Brasília, v. 4, n. 8, p. 293-302, dezembro de 2007.

Barros, Elionora Cavalcanti, Valentim, Márcia Cristina e Melo, Maria Amélia Aragão. O debate sobre o mestrado profissional na Capes: trajetória e definições. Revista Brasileira de Pós-Graduação, Brasília, v. 2, n. 4, p. 124-138, jul. 2005.

BELLONI, Maria Luiza. Educação à distância. Campinas: Editora Autores Associados, 2009.

CAEd. Centro de Políticas Públicas e Avaliação da Educação. http://institucional.caed.ufjf.br/ 2015.

CAPES. Portaria n. 80, de 16 de dezembro de 1998.

CAPES. Portaria n. 17, de 28 de dezembro de 2009.

CAPES. Sistema Nacional da Pós-graduação. Disponível em: http://conteudoweb.capes.gov. br/conteudoweb/ProjetoRelacaoCursosServlet?acao=pesquisarAreaAvaliacao Acesso em: 03/04/2015>, 2015.

Fischer, Tânia. Mestrado profissional como prática acadêmica. Revista Brasileira de Pós-Graduação, Brasília, v. 2, n. 4, p. 24-29, jul. 2005.

MENANDRO, P. R. M. Documentos e Debates: Réplica 2 - Mestrado Profissional, Você Sabe Com Quem Está Falando? RAC, Curitiba, v. 14, n. 2, pp. 367-371, Mar./Abr. 2010.

Moura Castro, Cláudio. A hora do mestrado profissional. Revista Brasileira de Pós-Graduação, Brasília, v. 2, n. 4, p. 16-23, jul. 2005. 
Pardim, Vanessa Itacaramby e Maccari, Emerson Antonio. A educação on-line na pós-graduação stricto sensu: a experiência de um Mestrado Profissional em Gestão e Avaliação da Educação Pública. Revista Brasileira de Pós-Graduação, Brasília, v. 11, n. 24, 2014.

PPGP/CAEd/UFJF. Ambiente Virtual de Aprendizagem. disponível em: http://www.ppgp2014. caedufjf.net/ 2015.

Preti, Oreste. Produção de Material Didático Impresso: orientações técnicas e pedagógicas.

Cuiabá: UAB/UFMT, 2010.

Ribeiro, Renato Janine. O mestrado profissional na política atual da Capes. Revista Brasileira de Pós-Graduação, Brasília, v. 2, n. 4, p. 8-15, jul. 2005.

Sanabio, Marcos Tanure; Magaldi, Juliana Alves (Org.). Relatório Sucupira - 2013, Mestrado Profissional em Gestão e Avaliação da Educação Pública, Juiz de Fora, CAEd/UFJF, 2014.

Sanabio, Marcos Tanure; Magaldi, Juliana Alves (Org.). Relatório Sucupira - 2014, Mestrado Profissional em Gestão e Avaliação da Educação Pública, Juiz de Fora, CAEd/UFJF, 2015. 